\title{
Molecular docking, synthesis and biological significance of pyrimidine analogues as prospective antimicrobial and antiproliferative agents
}

Sanjiv Kumar ${ }^{1}$, Archana Kaushik¹, Balasubramanian Narasimhan ${ }^{\text {* }}$ (1), Syed Adnan Ali Shah ${ }^{2,3}$, Siong Meng Lim², Kalavathy Ramasamy ${ }^{2,4}$ and Vasudevan Mani ${ }^{5}$

\begin{abstract}
Pyrimidine nucleus is a significant pharmacophore that exhibited excellent pharmacological activities. A series of pyrimidine scaffolds was synthesized and its chemical structures were confirmed by physicochemical and spectral analysis. The synthesized compounds were evaluated for their antimicrobial potential towards Gram positive and negative bacteria as well as fungal species. They were also assessed for their anticancer activity toward a human colorectal carcinoma cell line (HCT116). Whilst results of antimicrobial potential revealed that compounds $\mathbf{A x 2}$, Ax3, Ax8 and $\mathbf{A x 1 4}$ exhibited better activity against tested microorganisms, the results of antiproliferative activity indicated that compounds $\mathbf{A x 7}$ and $\mathbf{A x 1 0}$ showed excellent activity against HCT116. Further, the molecular docking of pyrimidine derivatives $\mathbf{A x 1} \mathbf{A x 9}$ and $\mathbf{A x 1 0}$ with CDK8 (PDB id: 5FGK) protein indicated that moderate to better docking results within the binding pocket. Compounds $\mathbf{A x} \mathbf{8}$ and $\mathbf{A x 1 0}$ having significant antimicrobial and anticancer activities may be selected as lead compounds for the development of novel antimicrobial and anticancer agent, respectively.
\end{abstract}

Keywords: Pyrimidine analogues, Antibacterial activity, Anticancer activity, Docking study

\section{Introduction}

Drug designing is a technique of searching and developing new molecules that exert specific action on a human kind [1]. The figure of multidrug resistant microbial infections is growing day by day which indicated that it is crucial to develop new class of antimicrobial drugs [2]. Tumor is a severe health issue and 2nd leading/most reason for mortality in the globe. It is caused by deregulation of the cell cycle which results in failure of cellular differentiation and unrestrained cellular growth $[3,4]$. So, it is necessary to develop and synthesize new bioactive molecules whose chemical structure and mode of action are noticeably differing from the available agents [5].

*Correspondence: naru2000us@yahoo.com

${ }^{1}$ Faculty of Pharmaceutical Sciences, Maharshi Dayanand University, Rohtak 124001, India

Full list of author information is available at the end of the article
Discovery of drug is a slow, lengthy costly and interdisciplinary procedure but the new developments have transformed the methods by which researchers generate new drug molecules e.g. CADD tool overcomes the cost of drug design up to $50 \%$ [1]. Molecular docking technique is used to understand the (i) drug-receptor interaction (ii) binding affinity (iii) orientation and approach of drug molecules to the target site. The main objectives of docking study are precise structural modeling, correct prediction of activity. It presents the most promising vision of drug-receptor interaction and generates a new rational approach to drug design [6]. RMSD is the average distance between the atoms of superimposed structures. This value is widely used parameter to rank the performance of docking methods. If the docked ligand shows $<2.0 \AA$ RMSD value with the crystallographic ligand, it is considered as a successful docking. To calculate the relative free energy, an accurate MM-GBSA binding affinity computation can also be applied $[7,8]$. 
Cyclin-dependent kinases play a significant role in the control of cell cycle. These holoenzymes have both catalytic (CDK) and regulatory (cyclin) subunits but present as higher order complexes that include additional proteins and are arbitrated by two classes of enzymes i.e. cyclin D- and E. The D-type cyclins (D1, D2 and D3) bind with two different catalytic sites (CDK4 and CDK6) to yield six possible holoenzymes that articulated in tissuespecific models [9].

CDKs are a class of enzymes that controls the cell cycle and are novel targets for prospective anticancer drugs [10]. A series of pyrimidines bearing 2-arylamino substituents was developed and screened for CDK1 and CDK2 inhibitory effect by Sayle et al. [11]. The SAR of 4-cyclohexylmethoxy-pyrimidines (inhibitors of CDK2) was explored [12]. The progression, transcription and other related functions of cell cycle are regulated by CDK8 that is a heterodimeric kinase protein. The carboxyterminal domain of RNA polymerase II is also phosphorylated by CDK-8. Hence, the inhibition of CDK-8 protein may be essential for regulating tumor $[6,13]$.

Pyrimidine is a heterocyclic nucleus containing nitrogen atom at 1 and 3 positions. It is the structural unit of DNA and RNA is an important molecule also plays a very significant role in the field of medicinal chemistry [14]. Pyrimidine is reported to have antimicrobial [15], anticancer [16, 17], anti-inflammatory [18], antioxidant [19], analgesic [20] and antiviral [21] and antimalarial [22] potentials. Number of marketed drugs contains pyrimidine ring such as proquazone (anti-inflammatory); idoxuridine (antiviral); trimethoprim (antibacterial); zidovudine (anti-HIV); pyrimethamine (antimalarial) and capecitabine (antiproliferative).

In the present study we have planned to synthesize heterocyclic pyrimidine analogues and evaluate their antimicrobial, antiproliferative and docking study.

\section{Results and discussion Chemistry}

Synthesis of heterocyclic pyrimidine analogues followed the general procedure discussed in synthetic Scheme 1. The reaction of $p$-substituted acetophenone with substituted benzaldehyde resulted in the formation of IntI. The resulted compound was treated with guanidine nitrate to yield pyrimidine ring (Int-II), which on reaction with corresponding substituted benzaldehyde in presence of glacial acetic acid yielded the final derivatives (Ax1-Ax19). The molecular scaffolds of the developed pyrimidine derivatives (Ax1-Ax19) were established by physicochemical properties (Table 1) and NMR, FTIR, MS spectra and elemental analysis (Table 2). The IR spectrum of synthesized compound showed bands around $2934-3093 \mathrm{~cm}^{-1}$ and $1462-1595 \mathrm{~cm}^{-1}$ which indicate the $\mathrm{C}-\mathrm{H}$ and $\mathrm{C}=\mathrm{C}$ group in aromatic nucleus, respectively. The $\mathrm{Ar}-\mathrm{Cl}$ group in compounds Ax5, Ax12, Ax16 were displayed stretches in the scale of $712-757 \mathrm{~cm}^{-1}$. The IR str. vibrations at $512-628 \mathrm{~cm}^{-1}$ in the spectral data of compounds displayed the $\mathrm{Ar}-\mathrm{Br}$ group at $p$-position of the aromatic nucleus. The existence of $\mathrm{Ar}-\mathrm{OCH}_{3}$ in synthesized analogues is established by absorption band around 1177-1276 $\mathrm{cm}^{-1}$. The appearance of IR str. $1550-1685 \mathrm{~cm}^{-1}$ in the compounds (Ax1-Ax19) specified the existence of $\mathrm{N}=\mathrm{CH}$ group. The $A r-\mathrm{NO}_{2}$ group in compounds Ax1, Ax6 and Ax15-Ax19 were displayed by symmetric $\mathrm{Ar}-\mathrm{NO}_{2}$ str. in the scale of $1345-1462 \mathrm{~cm}^{-1}$. The IR stretching $1270-1363 \mathrm{~cm}^{-1}$ of synthesized compounds specified the existence of $\mathrm{C}-\mathrm{N}$ group. The impression of IR absorption band at 3231$3491 \mathrm{~cm}^{-1}$ in the spectral data of the molecules displayed the presence of Ar-OH group on the aromatic nucleus. The signals between 6.39 and $8.38 \delta$ in NMR spectra are indicative of aromatic proton. The prepared derivatives exhibited singlet at 7.46-8.39 $\delta$ due to the presence of $\mathrm{N}=\mathrm{CH}$ group in pyrimidine nucleus. Molecules displayed singlet at 7.56-7.91 $\delta$ due to the presence of $-\mathrm{CH}$ group in pyrimidine nucleus. The singlet at $3.71-3.87 \delta$ indicated the presence $\mathrm{Ar}-\mathrm{OCH}_{3}$. Compound $\mathrm{Ax8}$ exhibited singlet at $2.67 \delta$ due to presence of $-\mathrm{N}\left(\mathrm{CH}_{3}\right)_{2}$ at the $p$-position. The compound Ax14 exhibited quadrate at $3.38 \delta$ and triplet at $1.14 \delta$ due to presence of $-\mathrm{N}\left(\mathrm{C}_{2} \mathrm{H}_{5}\right)_{2}$ group at $p$-position. The ${ }^{13} \mathrm{C}$-NMR spectra of aromatic ring exhibited in the range of 102.0, 112.3, 117.3, 123.6, $124.4,126.6,126.3,128.1,129.3,130.2,133.2,147.5$, 153.2; pyrimidine nucleus exhibited around 111.5, 164.3, 168.2; $\mathrm{N}=\mathrm{CH}$ group exhibited around 161.0; $\mathrm{OCH}_{3}$ group showed around 54.1, 60.8, 56.1. The elemental analysis $(\mathrm{CHN})$ was found within $\pm 0.4 \%$ of the theoretical results of derivatives.

\section{Antimicrobial screening results}

The pyrimidine compounds (Ax1-Ax19) were examined for their antimicrobial potency towards Gram -ve and Gram +ve bacteria as well as fungal species by tube dilution technique. Table 3, Figs. 1 and 2 show the antimicrobial evaluation results. The compounds showed significant antimicrobial activity than standard drugs, norfloxacin (for antibacterial study) and fluconazole (for antifungal study). In Gram negative bacteria, compound Ax14 $\left(\mathrm{MIC}_{e c}=21.7 \mu \mathrm{M}\right)$ exhibited better antibacterial potency toward E. coli. In the case of Gram positive bacteria, compound Ax8 $\left(\mathrm{MIC}_{s a}=21.2 \mu \mathrm{M}\right)$ and $\left(\mathrm{MIC}_{b s}=10.6 \mu \mathrm{M}\right)$ showed the significant potency towards $S$. aureus and B. subtilis, respectively. The antifungal screening results displayed that compounds, Ax2 $\left(\mathrm{MIC}_{a n}=9.40 \mu \mathrm{M}\right)$ and $\mathrm{Ax3}\left(\mathrm{MIC}_{c a}=10.7 \mu \mathrm{M}\right)$ showed the significant potency towards $A$. niger and $C$. albicans, 
$\mathbf{a}$<smiles>COc1cc(/C=N/c2nc(-c3ccc([N+](=O)[O-])cc3)cc(-c3c(O)ccc4ccccc34)n2)cc(OC)c1OC</smiles>
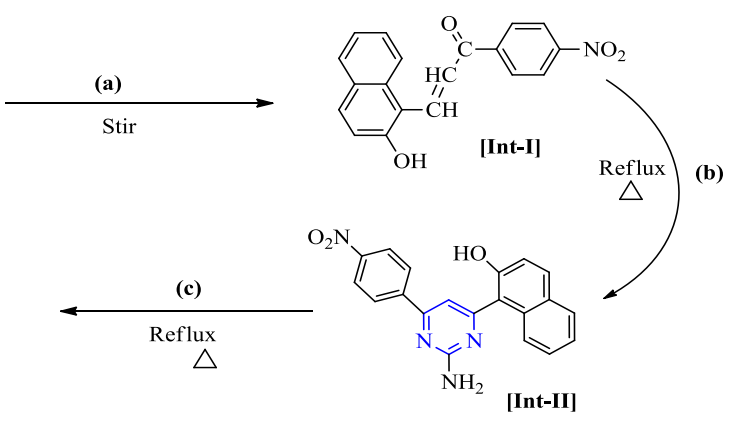

Reaction condition:

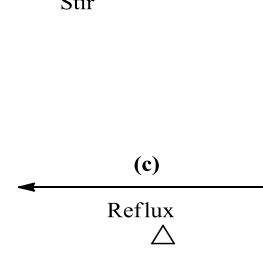

(a): $p$-Nitroacetophenone, naphthaldehyde, methanol, $\mathrm{NaOH}$, stirred $30 \mathrm{~min}\left(20-22^{\circ} \mathrm{C}\right)$; (b): Guanidine nitrate, $\mathrm{HCl}, \mathrm{KOH}$, methanol, reflux 5-6 h (RT); (c): 3,4,5-Trimethoxybenzaldehyde, glacial acetic acid, reflux 2-3 h (RT)

b

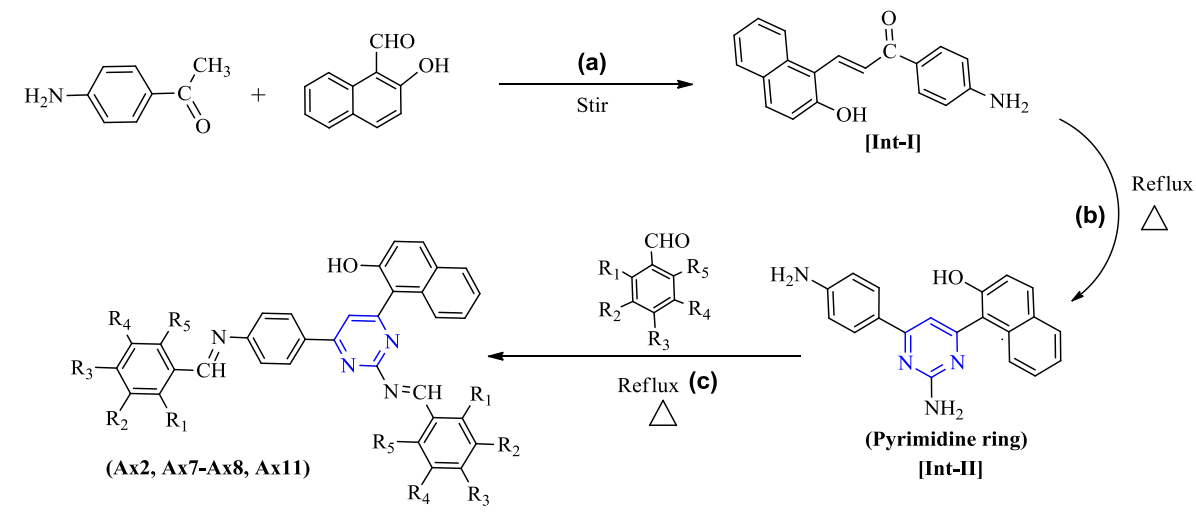

Ax2. $\mathrm{R}_{1}=\mathrm{R}_{2}=\mathrm{R}_{4}=\mathrm{R}_{5}=\mathrm{H} ; \mathrm{R}_{3}=\mathrm{Br}$;

Ax7. $\mathrm{R}_{1}=\mathrm{R}_{2}=\mathrm{R}_{4}=\mathrm{R}_{5}=\mathrm{H} ; \mathrm{R}_{3}=\mathrm{OCH}_{3}$

Ax8. $\mathrm{R}_{1}=\mathrm{R}_{2}=\mathrm{R}_{4}=\mathrm{R}_{5}=\mathrm{H} ; \mathrm{R}_{3}=\mathrm{N}\left(\mathrm{CH}_{3}\right)_{2} ; \quad$ Ax11. $\mathrm{R}_{2}=\mathrm{R}_{3}=\mathrm{R}_{4}=\mathrm{R}_{5}=\mathrm{H} ; \mathrm{R}_{1}=\mathrm{OCH}_{3}$

Reaction condition:

(a): 1-(4-Aminophenyl) ethanone, 2-Hydroxynaphthalene-1-carbaldehyde, methanol, $\mathrm{NaOH}$, stirred $30 \mathrm{~min}\left(20-22{ }^{\circ} \mathrm{C}\right)$;

(b): Guanidine nitrate, $\mathrm{HCl}, \mathrm{KOH}$, methanol, reflux 5-6 h (RT); (c): Substituted benzaldehyde, glacial acetic acid, reflux 2-3 h (RT)

c<smiles>[X]c1ccc(C(C)=O)cc1</smiles>

Ax3. $\mathrm{X}=\mathrm{Br} ; \mathrm{R}_{1}=\mathrm{R}_{2}=\mathrm{R}_{4}=\mathrm{R}_{5}=\mathrm{H} ; \mathrm{R}_{3}=\mathrm{Br}$

Ax4. $X=B r ; R_{1}=R_{2}=R_{4}=R_{5}=H ; R_{3}=O H$

Ax5. $\mathrm{X}=\mathrm{Br} ; \mathrm{R}_{1}=\mathrm{R}_{3}=\mathrm{R}_{4}=\mathrm{R}_{5}=\mathrm{H} ; \mathrm{R}_{2}=\mathrm{Cl}$

Ax6. $X=B r ; R_{1}=R_{2}=R_{4}=R_{5}=H ; R_{3}=\mathrm{NO}_{2}$

Ax9. $\mathrm{X}=\mathrm{Br} ; \mathrm{R}_{2}=\mathrm{R}_{3}=\mathrm{R}_{5}=\mathrm{H} ; \mathrm{R}_{1}=\mathrm{OH} ; \mathrm{R}_{4}=\mathrm{Br}$

Ax10. $X=B r ; R_{2}=R_{3}=R_{4}=R_{5}=H ; R_{1}=O H$

Ax12. $X=B r ; R_{2}=R_{3}=R_{4}=R_{5}=H ; R_{1}=C l$

Ax13. $\mathrm{X}=\mathrm{Br}$

Ax14. $X=B r ; R_{1}=R_{2}=R_{4}=R_{5}=H ; R_{3}=N\left(C_{2} H_{5}\right)_{2}$

Ax15. $\mathrm{X}=\mathrm{NO}_{2} ; \mathrm{R}_{1}=\mathrm{R}_{3}=\mathrm{R}_{4}=\mathrm{R}_{5}=\mathrm{H} ; \mathrm{R}_{2}=\mathrm{Br}$

Ax16. $\mathrm{X}=\mathrm{NO}_{2} ; \mathrm{R}_{2}=\mathrm{R}_{3}=\mathrm{R}_{4}=\mathrm{R}_{5}=\mathrm{H} ; \mathrm{R}_{1}=\mathrm{Cl}$

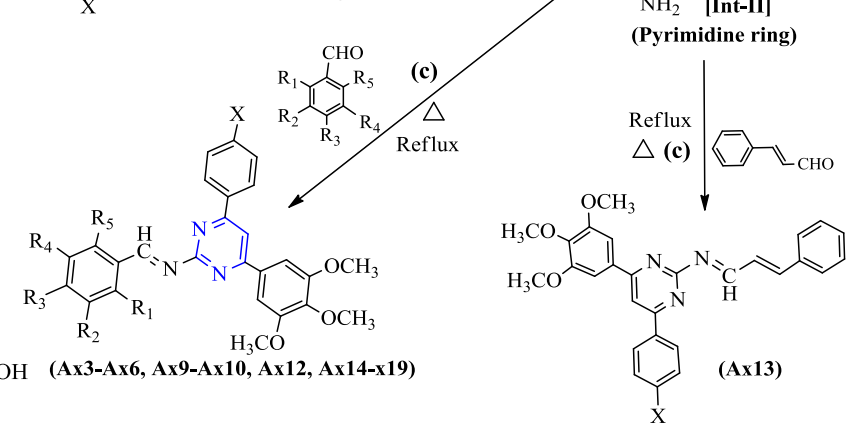

Ax17. $\mathrm{X}=\mathrm{NO}_{2} ; \mathrm{R}_{1}=\mathrm{R}_{4}=\mathrm{R}_{5}=\mathrm{H} ; \mathrm{R}_{2}=\mathrm{OC}_{2} \mathrm{H}_{5} ; \mathrm{R}_{3}=\mathrm{OH} \quad(\mathbf{A x 3} 3-\mathrm{Ax6}, \mathbf{A x 9 - A x 1 0 ,}$ Ax12, Ax14-x19)

Ax18. $X=\mathrm{NO}_{2} ; \mathrm{R}_{2}=\mathrm{R}_{3}=\mathrm{R}_{4}=\mathrm{R}_{5}=\mathrm{H} ; \mathrm{R}_{1}=\mathrm{OCH}_{3}$

Ax19. $\mathrm{X}=\mathrm{NO}_{2} ; \mathrm{R}_{2}=\mathrm{R}_{3}=\mathrm{R}_{5}=\mathrm{H} ; \mathrm{R}_{1}=\mathrm{OH} ; \mathrm{R}_{4}=\mathrm{Br}$

Reaction condition:

(a): $p$-Substituted acetophenone, 3,4,5-trimethoxybenzaldehyde, methanol, $\mathrm{NaOH}$, stirred $30 \mathrm{~min}\left(20-22{ }^{\circ} \mathrm{C}\right)$; (b): Guanidine nitrate, $\mathrm{HCl}, \mathrm{KOH}$, methanol, reflux 5-6 h (RT); (c): Substituted benzaldehyde, glacial acetic acid, reflux 2-3 h (RT)

Scheme 1 Synthesis of heterocyclic pyrimidine derivatives (Ax1-Ax19) 


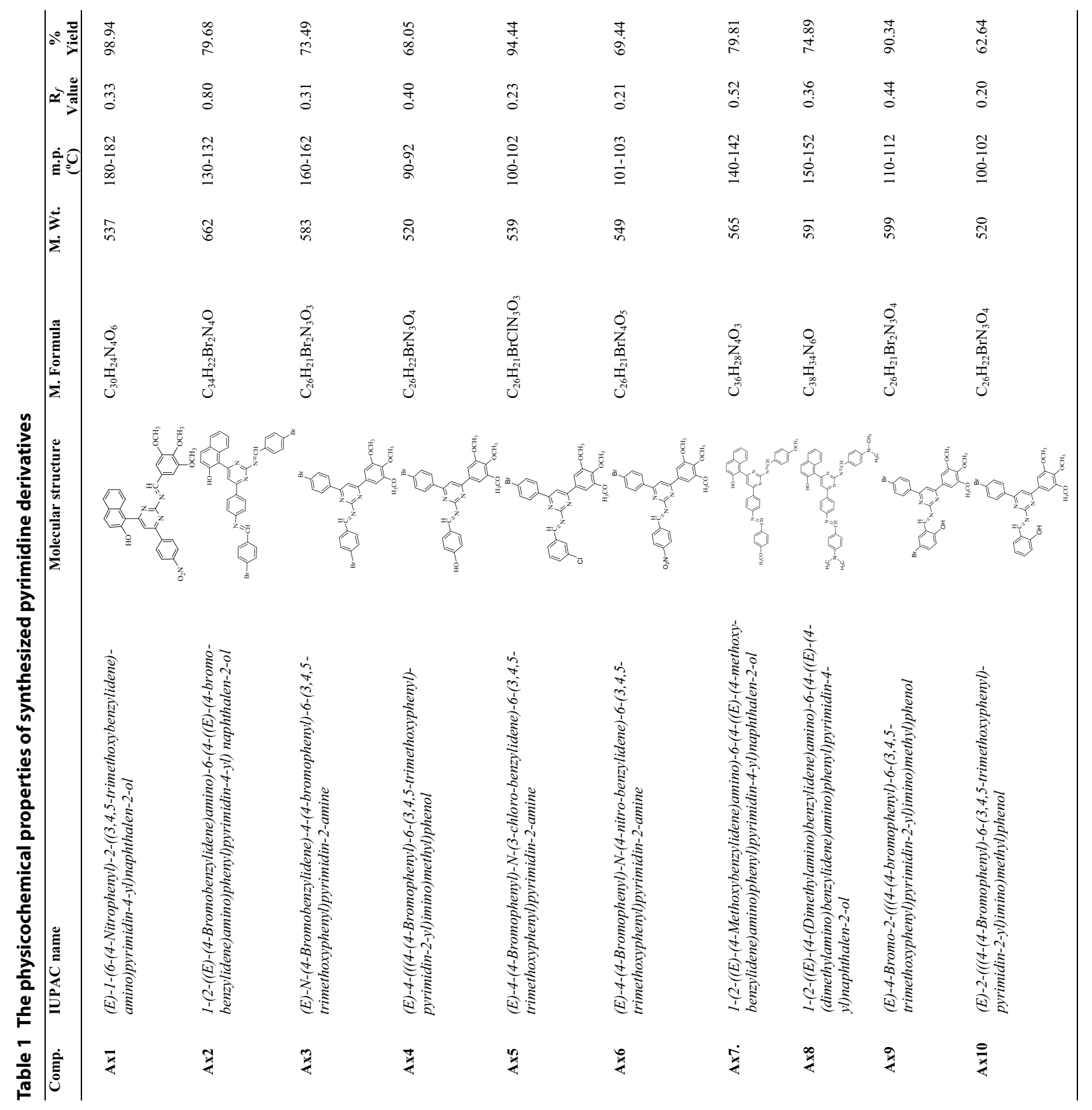




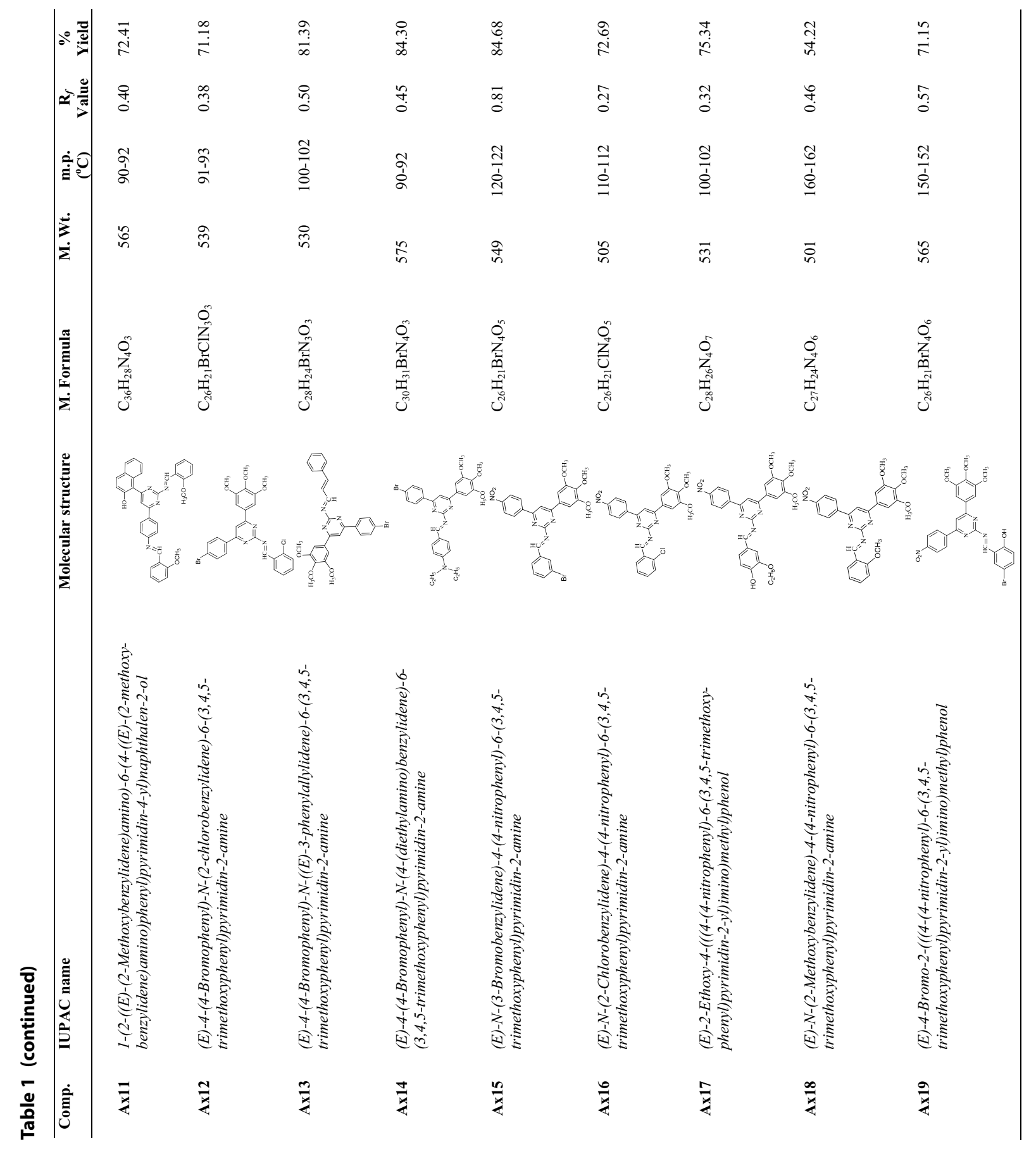




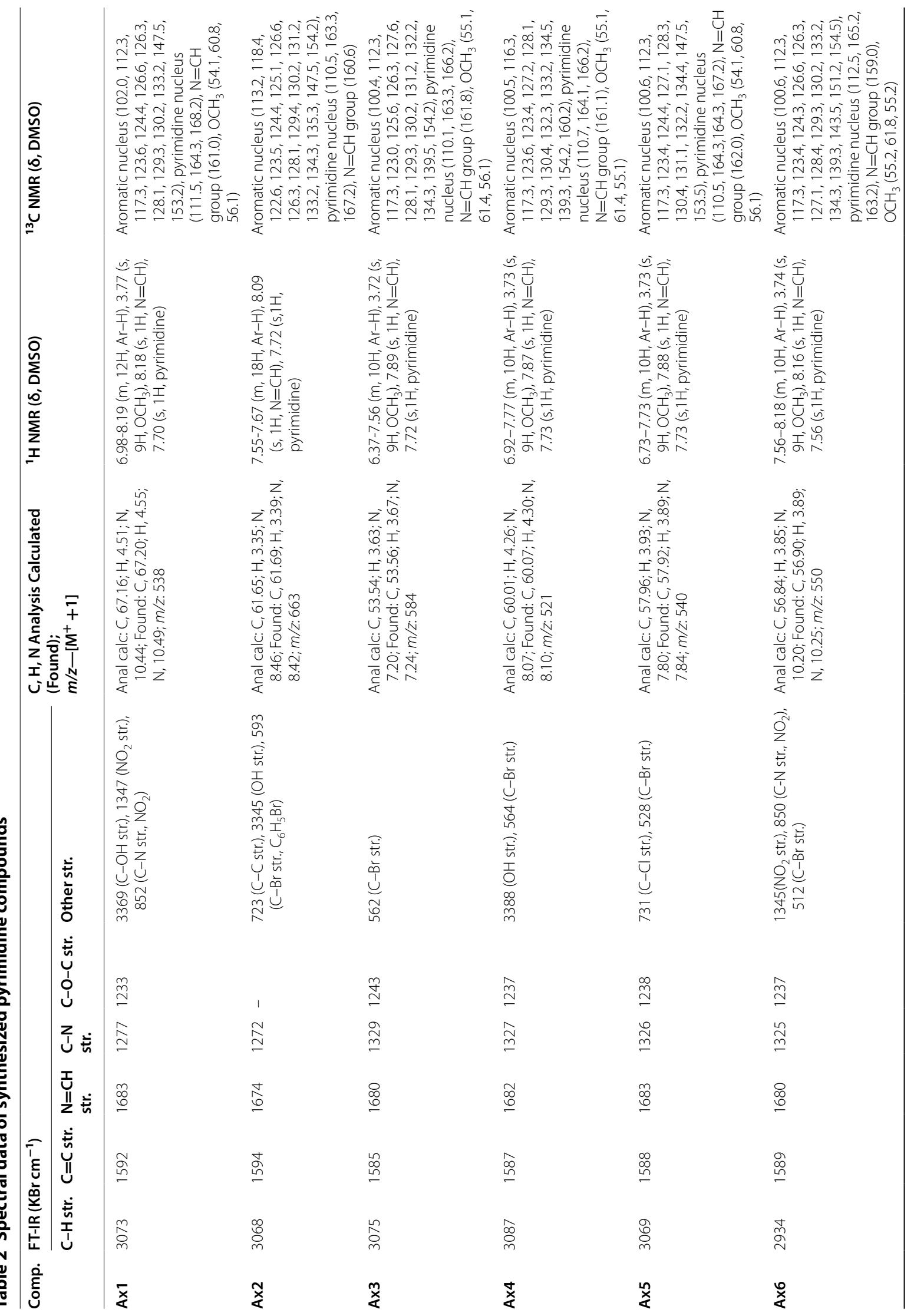




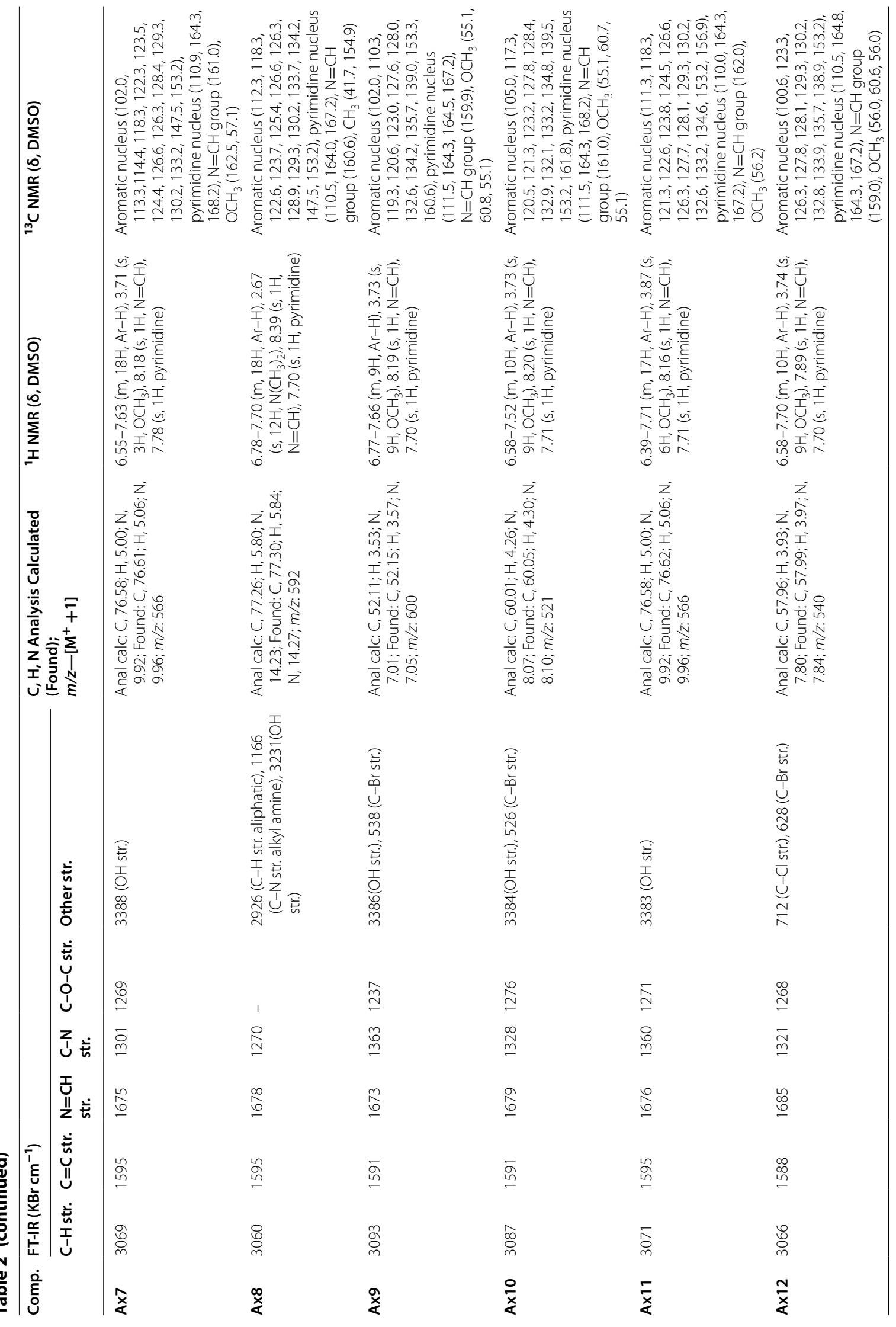




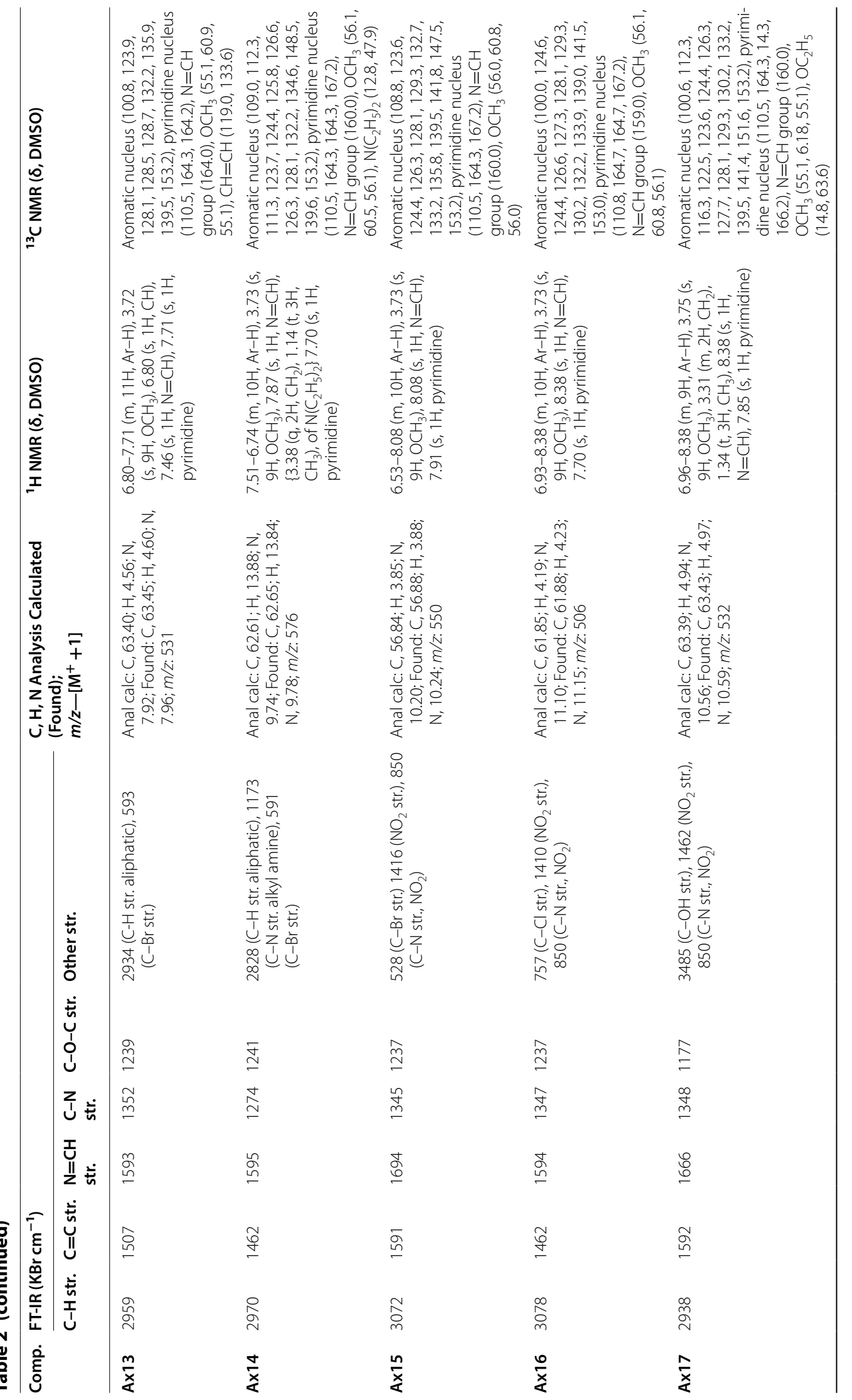




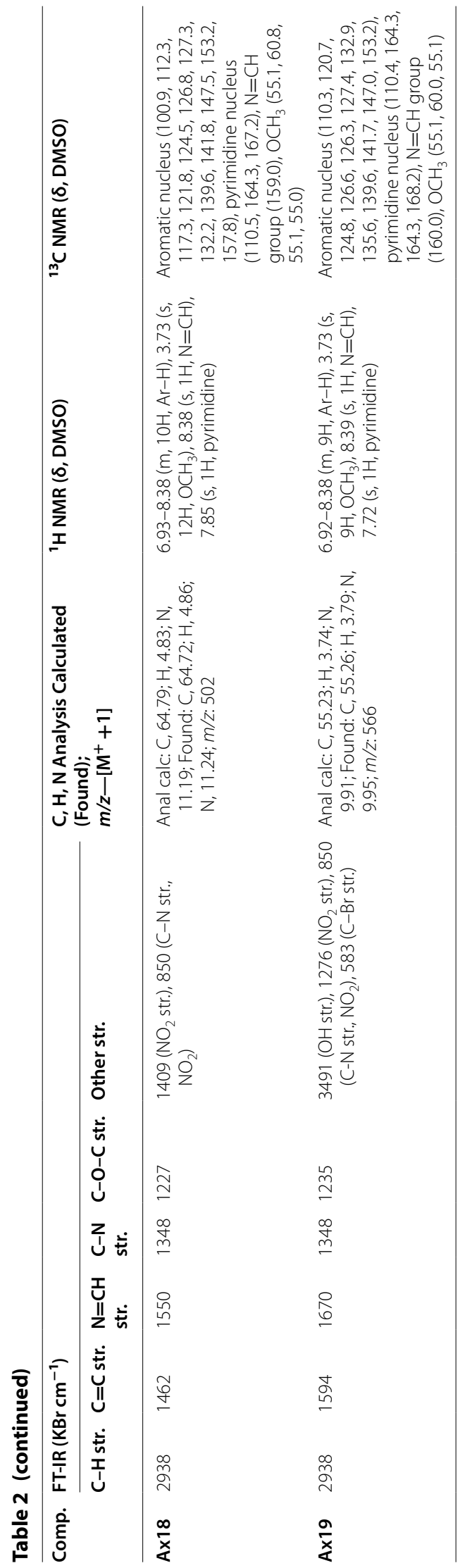


Table 3 Antimicrobial activity results of synthesized heterocyclic pyrimidine derivatives

\begin{tabular}{|c|c|c|c|c|c|}
\hline \multirow[t]{3}{*}{ Comp. } & \multicolumn{5}{|c|}{$\begin{array}{l}\text { Antimicrobial activity } \\
\text { Minimum inhibitory concentration }(\mathrm{MIC}=\mu \mathrm{M})\end{array}$} \\
\hline & \multicolumn{3}{|c|}{$\begin{array}{l}\text { Bacteria species (Gram+ } \\
\text { and Gram-) }\end{array}$} & \multicolumn{2}{|c|}{ Fungal species } \\
\hline & S.A. & B.S. & E.C. & C.A. & A.N. \\
\hline$A \times 1$ & 23.3 & 23.3 & 46.6 & 23.3 & 23.3 \\
\hline$A \times 2$ & 37.8 & 18.9 & 37.8 & 37.8 & 9.40 \\
\hline$A \times 3$ & 42.9 & 21.4 & 85.8 & 10.7 & 21.4 \\
\hline Ax4 & 24.0 & 24.0 & 48.1 & 12.0 & 24.0 \\
\hline Ax5 & 46.4 & 23.2 & 23.2 & 11.6 & 23.2 \\
\hline Ax6 & 22.8 & 22.8 & 45.5 & 11.4 & 22.8 \\
\hline$A \times 7$ & 22.1 & 11.1 & 44.2 & 11.1 & 22.1 \\
\hline Ax8 & 21.2 & 10.6 & 42.3 & 21.2 & 21.2 \\
\hline$A \times 9$ & 41.7 & 41.7 & 41.7 & 20.9 & 41.7 \\
\hline Ax10 & 24.0 & 24.0 & 24.0 & 12.0 & 48.1 \\
\hline Ax11 & 44.2 & 11.1 & 44.2 & 22.1 & 22.1 \\
\hline$A \times 12$ & 23.2 & 23.2 & 46.4 & 23.2 & 23.2 \\
\hline$A \times 13$ & 47.2 & 23.6 & 47.2 & 23.6 & 23.6 \\
\hline$A \times 14$ & 21.7 & 10.9 & 21.7 & 10.9 & 10.9 \\
\hline Ax15 & 22.8 & 22.8 & 22.8 & 11.4 & 22.8 \\
\hline Ax16 & 49.6 & 24.8 & 24.8 & 12.4 & 24.8 \\
\hline Ax17 & 23.5 & 23.5 & 23.5 & 11.8 & 23.5 \\
\hline Ax18 & 25.0 & 25.0 & 49.9 & 12.5 & 25.0 \\
\hline Ax19 & 22.1 & 22.1 & 44.2 & 22.1 & 22.1 \\
\hline Std. & $47.0^{x}$ & $47.0^{x}$ & $47.0^{x}$ & $50.0^{y}$ & $50.0^{y}$ \\
\hline DMSO & NA & NA & NA & NA & NA \\
\hline Broth control & $N G$ & NG & NG & $N G$ & NG \\
\hline
\end{tabular}

Std drugs: ${ }^{\times}$Norfloxacin; ${ }^{{ }}$Fluconazole; S.A., Staphylococcus aureus; B.S., Bacillus subtilis; E.C., Escherichia coli; C.A., Candida albicans; A.N., Aspergillus niger; NA, no activity; NG, no growth

respectively. The molecules may be used as the lead compounds for the development of new antimicrobial agents.

\section{Antiproliferative screening results}

Table 4 and Fig. 3 show the screening results of the developed pyrimidine compounds (Ax1-Ax19) towards human colorectal carcinoma cell line by SRB assay [23]. The synthesized compounds exhibited good anticancer activity, with some of the findings comparable or highly potent than 5 -fluorouracil (standard drug). Compounds Ax2 $\left(\mathrm{IC}_{50}=2.70 \mu \mathrm{M}\right), \mathbf{A x} 7\left(\mathrm{IC}_{50}=1.90 \mu \mathrm{M}\right), \mathbf{A x 8}$ $\left(\mathrm{IC}_{50}=2.20 \mu \mathrm{M}\right)$ and $\mathrm{Ax10}\left(\mathrm{IC}_{50}=0.80 \mu \mathrm{M}\right)$, in particular, were the four best compounds which elicited more potent anticancer activity when compared to the reference drug $\left(\mathrm{IC}_{50}=6.20 \mu \mathrm{M}\right)$. They may be used as lead molecules for the development of new anticancer agent.

\section{Molecular docking results}

The CDKs is an enzyme family that plays an significant role in the regulation of the cell cycle and thus is an especially advantageous target for the development of small inhibitory molecules [13]. The crystal structure of cyclin dependent kinase 8 (PDB Id: 5FGK) which has a good resolution of about $2.36 \AA$ was used for docking study. The binding site of the target was generated using co-crystallized ligand (5XG) as reference $(\mathrm{X}=-0.138$, $\mathrm{Y}=-24.891, \mathrm{Z}=150.623)$. Root-mean square deviation (RMSD) value of docked pose of native co-crystallized ligand was calculated as $0.08 \AA$. The synthesized pyrimidine compounds were then docked to the active site of CDK8. The docking results were analysed based on the docking score obtained from GLIDE. Among the docked compounds, compounds Ax1, Ax9 and Ax10 displayed moderate to good docked score with anticancer potency against a HCT116 cancer cell line. Ligand interaction image and binding mode of compounds Ax1, Ax9 and Ax10 in the active site of CDK8 protein having co-crystallized ligand 5XG and 5-Fu is having a different binding mode to that of active compounds (Figs. 4, 5, 6 and 7). The molecular docking results depend on the statistical evaluation function according to which the interaction energy in numerical values as docking scores [24].

Molecular docking study of the selected compounds have good to better anticancer potency toward cancer cell line were displayed moderate to better docking score within binding pocket. Binding mode of active compounds Ax1, Ax9 and Ax10 within the binding region, compound Ax10 have moderate docked score (-4.191) with better potency $(0.80 \mu \mathrm{M})$ and formation of pi-cation interaction with amino acid residue Arg356; compound Ax1 have better docked score $(-5.668)$ with lowest potency $(48.4 \mu \mathrm{M})$ and formation of $\mathrm{H}$-bond with amino acid residues Val27 and Lys153, pi-cation interaction with Arg356 and salt bridge with Asp173, Lys52 and Glu66 within the binding pocket and compound Ax9 have moderate docked score $(-4.477)$ with moderate potency $(16.7 \mu \mathrm{M})$ and formation of $\mathrm{H}$-bond with amino acid residue Lys 153 within the binding pocket and compared to 5 -fluorouracil have better docked score $(-5.753)$ with good potency $(6.20 \mu \mathrm{M})$ and formation of $\mathrm{H}$-bond with amino acid residues Ala100 and Asp98 within binding pocket. The docking score results and interacting residues are showing in Table 5. Thus the docking analyses suggested that the pyrimidines can act as of great interest in successful chemotherapy. Cyclin dependent kinase-8 may be the target protein of pyrimidine derivatives for their antiproliferative activity. 


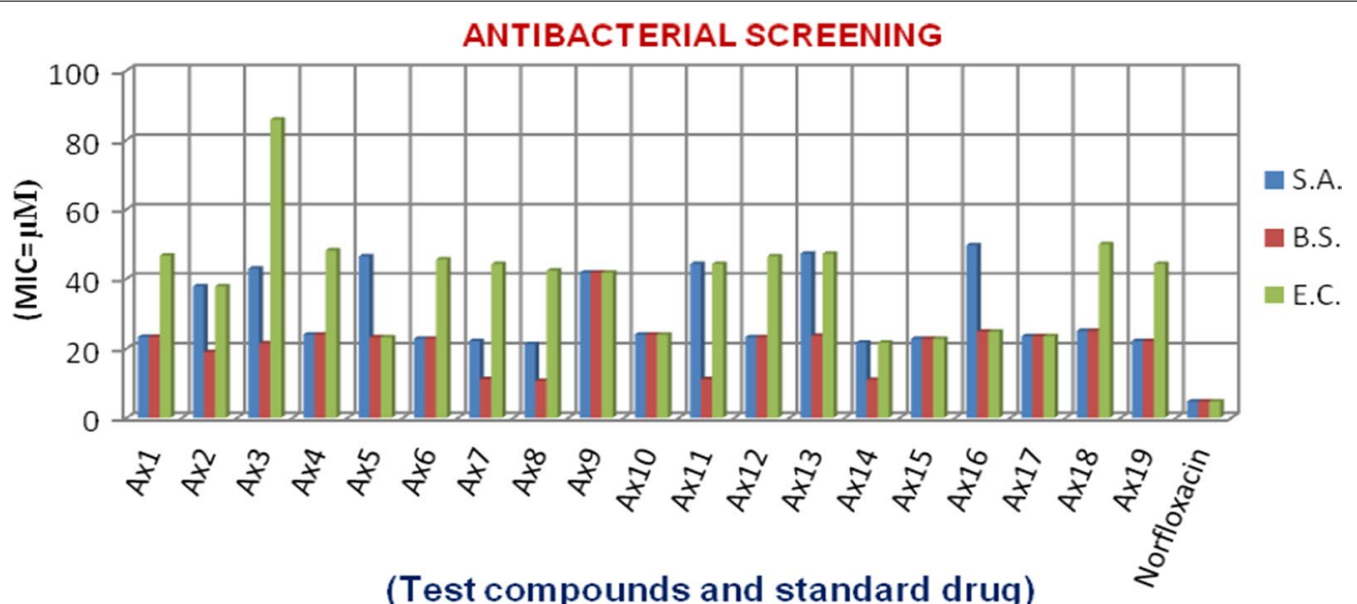

Fig. 1 Antibacterial screening graph of synthesized compounds

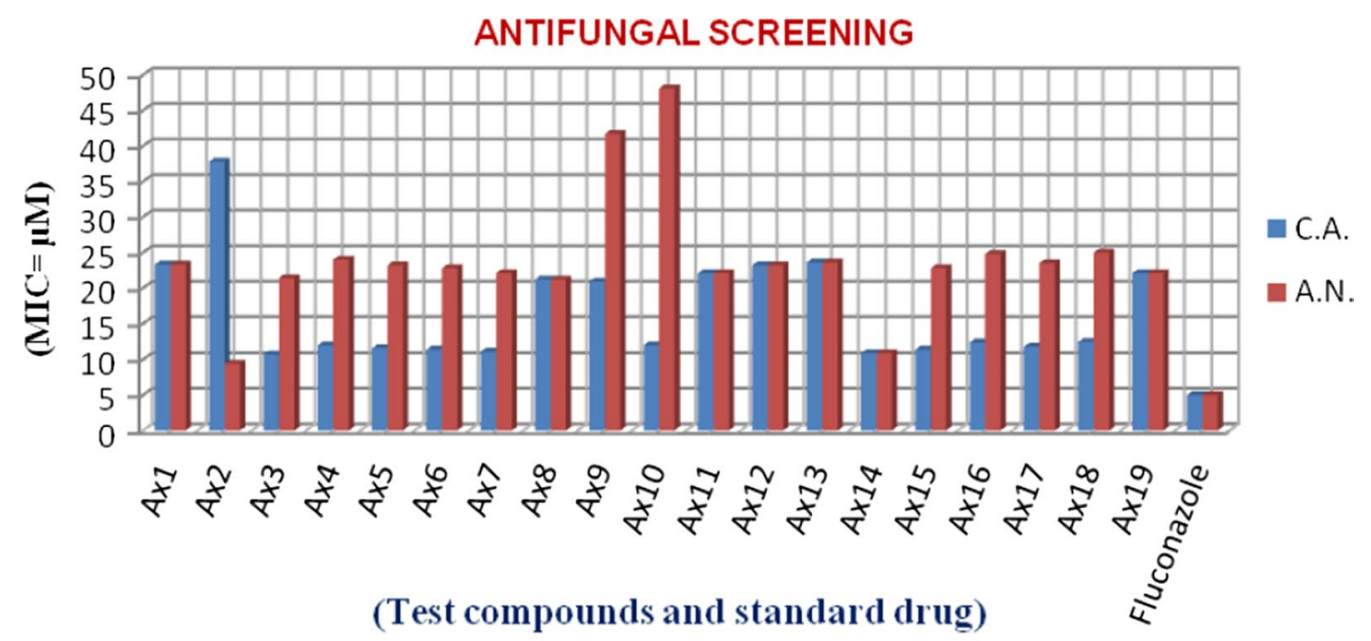

Fig. 2 Antifungal screening graph of synthesized compounds

Table 4 Antiproliferative activity of synthesized pyrimidine derivatives

\begin{tabular}{lccc}
\hline Anticancer activity & $\left(\mathrm{IC}_{\mathbf{5 0}}=\boldsymbol{\mu M}\right)$ & & \\
\hline Comp. & $\begin{array}{l}\text { Cancer cell } \\
\text { (HCT1 16) }\end{array}$ & $\mathbf{C o m p}$. & $\begin{array}{l}\text { Cancer cell } \\
\text { (HCT116) }\end{array}$ \\
\hline $\mathbf{A x 1}$ & 48.4 & $\mathbf{A x 1 1}$ & 3.0 \\
$\mathbf{A x 2}$ & 2.70 & $\mathbf{A x 1 2}$ & 111.3 \\
$\mathbf{A x 3}$ & 61.7 & $\mathbf{A x 1 3}$ & 15.1 \\
$\mathbf{A x 4}$ & 42.3 & $\mathbf{A x 1 4}$ & 69.6 \\
$\mathbf{A x 5}$ & 31.5 & $\mathbf{A x 1 5}$ & 94.7 \\
$\mathbf{A x 6}$ & 43.7 & $\mathbf{A x 1 6}$ & 13.9 \\
Ax7 & 1.90 & $\mathbf{A x 1 7}$ & 75.3 \\
Ax8 & 2.20 & $\mathbf{A x 1 8}$ & 3.60 \\
Ax9 & 16.7 & $\mathbf{A x 1 9}$ & 12.4 \\
Ax10 & 0.80 & & \\
5-fluorouracil & 6.20 & & \\
\hline
\end{tabular}

SAR (structure activity relationship) study

The following SAR can be deduced from the antimicrobial and anticancer screening results of pyrimidine analogues (Fig. 8).

\section{Antimicrobial activity}

The presence of EWG (electron withdrawing group) (inductively) $-\mathrm{Br}$ at $p$-position of the substituted benzylidene aromatic nucleus of compound Ax2 improved the antifungal activity against $A$. niger and $\left.-\mathrm{N}\left(\mathrm{CH}_{3}\right)_{2}\right)$ (an electron donating group, by mesomeric affect) at $p$-position of the benzylidene nucleus of compound Ax8 enhanced the antibacterial activity towards $S$. aureus and B. subtilis.

On the other side, The presence of EWG (inductively) $-\mathrm{Br}$ at $p$-position of the substituted benzylidene 


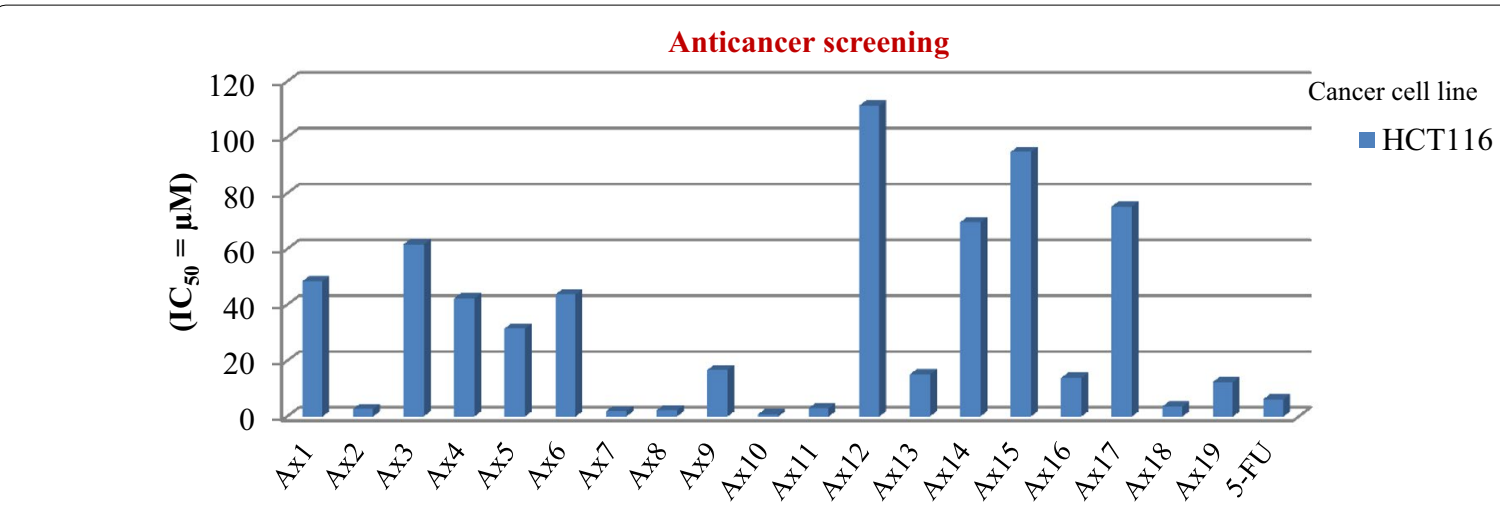

(Test compounds and standard drug)

Fig. 3 Anticancer screening graph of synthesized compounds

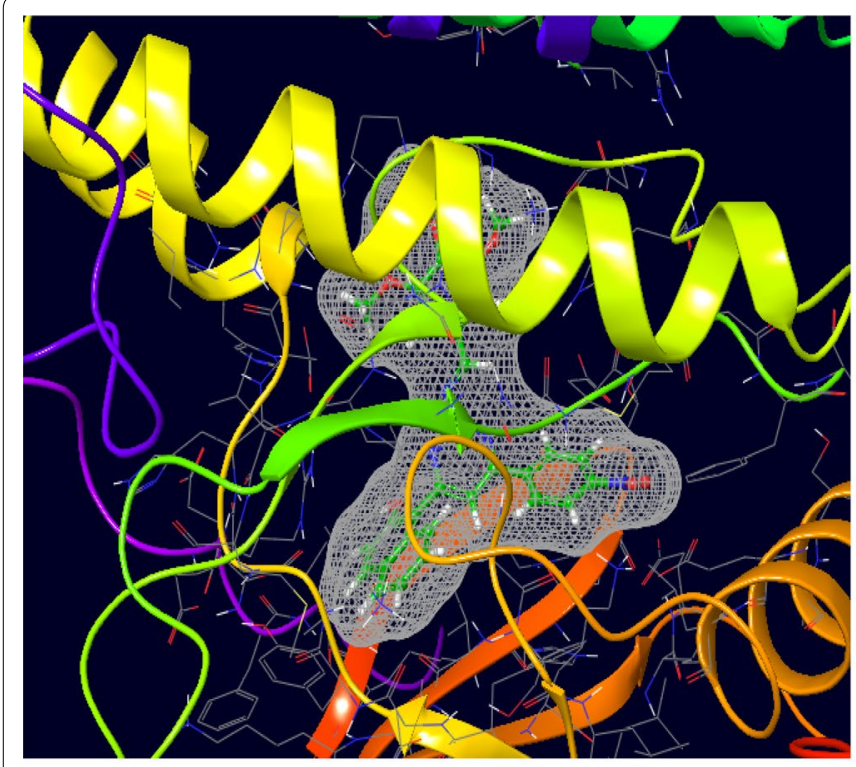

Binding surface

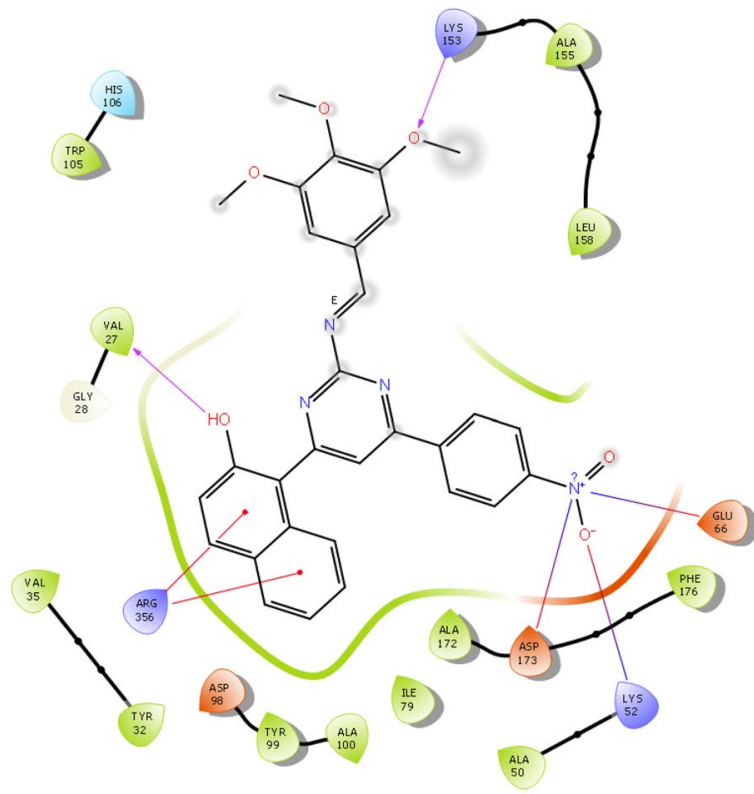

2D ligand interaction

Fig. 4 Binding surface and 2D ligand interaction diagram of compound Ax1

aromatic nucleus of compound $\mathbf{A x} \mathbf{3}$ improved the antifungal activity toward C. albicans and $\left.-\mathrm{N}\left(\mathrm{C}_{2} \mathrm{H}_{5}\right)_{2}\right)$ (an electron donating group, by mesomeric affect) at $p$-position the substituted benzylidene aromatic ring of compound Ax14 enhanced the antibacterial activity towards E. coli.

\section{Anticancer activity}

The presence of EWG (inductively) - Br at $p$-position of the substituted benzylidene aromatic nucleus of compounds Ax2 and $\left.-\mathrm{N}\left(\mathrm{CH}_{3}\right)_{2}\right)$ (an electron donating group, by mesomeric affect) at $p$-position of the substituted benzylidene aromatic ring of compound Ax8 enhanced the anticancer activity towards a human colorectal carcinoma cell line (HCT116), however, electron releasing groups like $p-\mathrm{OCH}_{3}$ and $o-\mathrm{OH}$ on substituted benzylidene aromatic ring of compounds Ax7 and Ax10, respectively showed significant role in improving the anticancer activity toward a HCT116 cell line. The SAR study is consistent the results of Kumar et al. $[6,15]$ and Xu et al. [25]. 


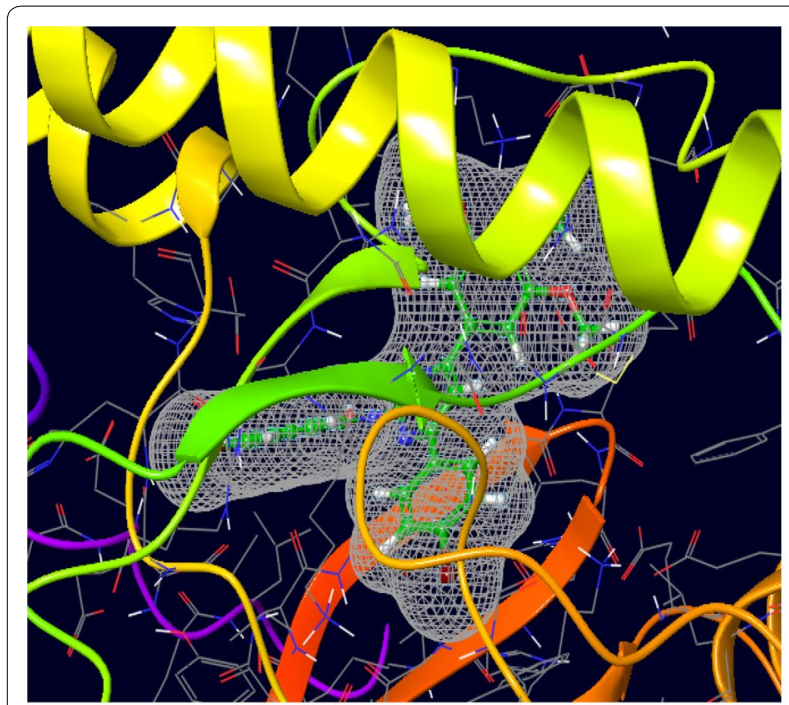

Binding surface

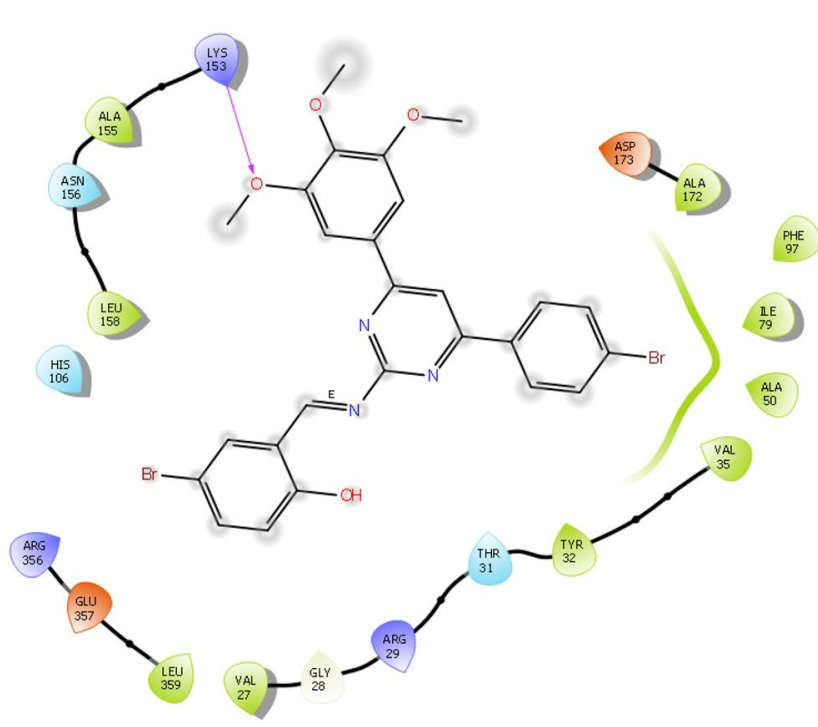

2D ligand interaction

Fig. 5 Binding surface and 2D ligand interaction diagram of compound $\mathbf{A x} \mathbf{9}$

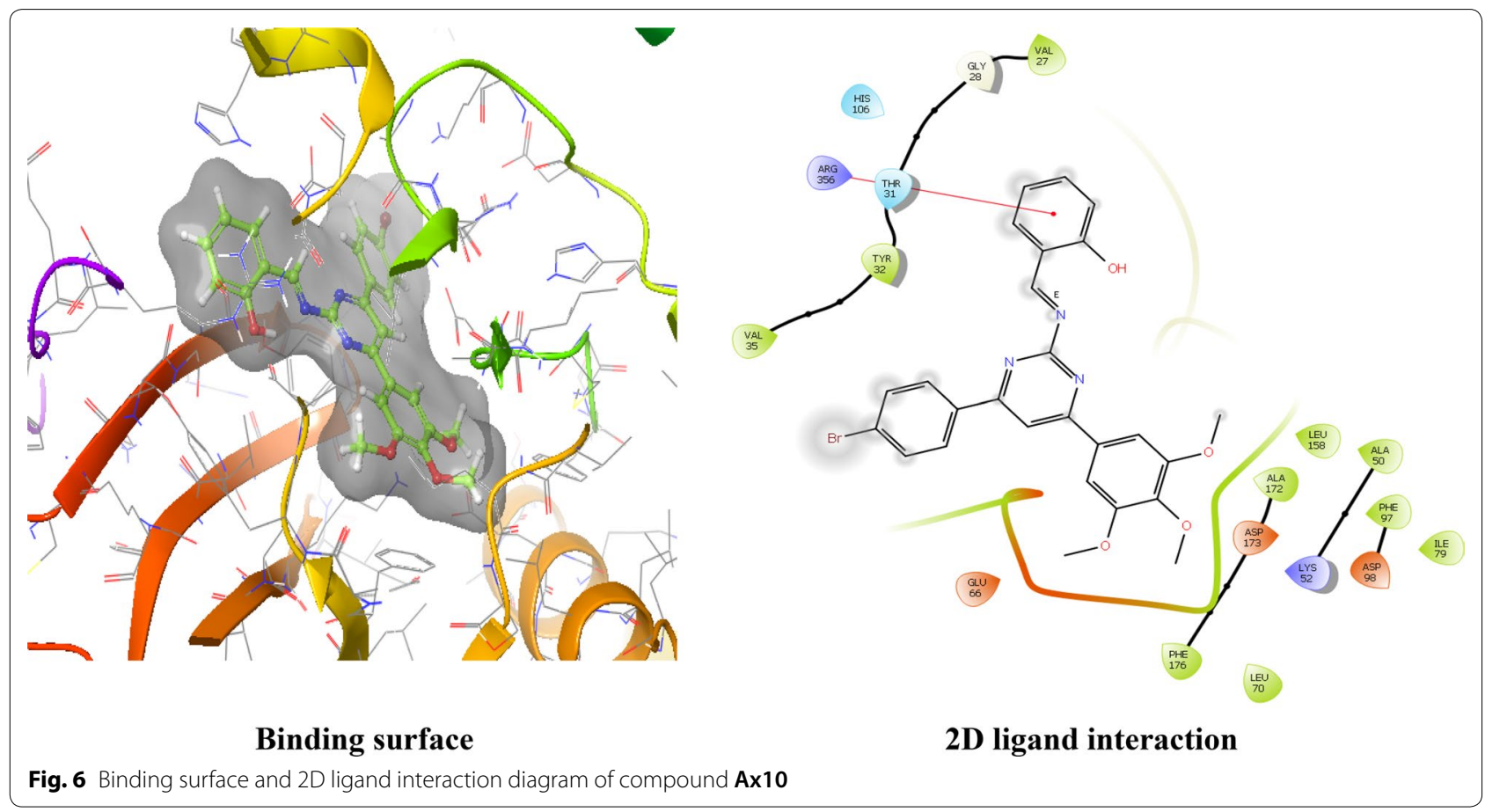

\section{Experimental}

Preparatory materials were obtained from commercial sources [CDH Pvt. Ltd, HiMedia Lab. Pvt. Ltd. and Loba Chemie, Pvt Ltd. Mumbai, India] for the research work. Reaction advancement was observed by TLC (silica gel plates) using chloroform: methanol as mobile phase. Melting point was determined in open capillary tube method. Elemental analysis of the derivatives was determined by Perkin-Elmer $2400 \mathrm{C}, \mathrm{H}$ and $\mathrm{N}$ instrument. FTIR spectrum was recorded on Bruker 12060280 spectrometer. The Mass spectrum of the molecules was recorded on Waters Micromass Q-ToF Micro instrument. ${ }^{1} \mathrm{H}-\mathrm{NMR}$ and ${ }^{13} \mathrm{C}$-NMR were recorded at $600 \mathrm{MHz}$ 


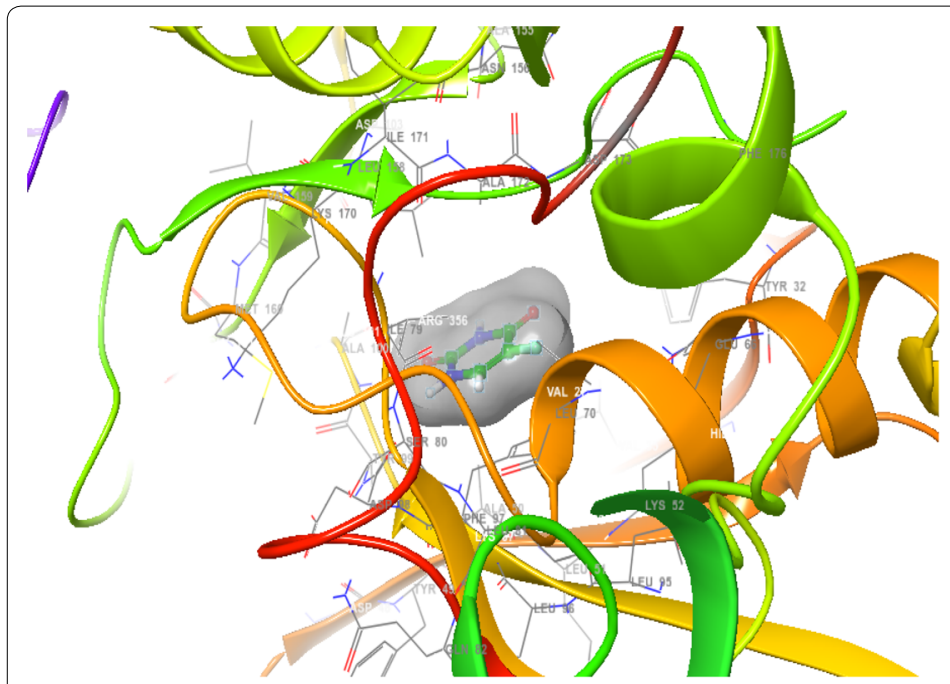

Binding surface

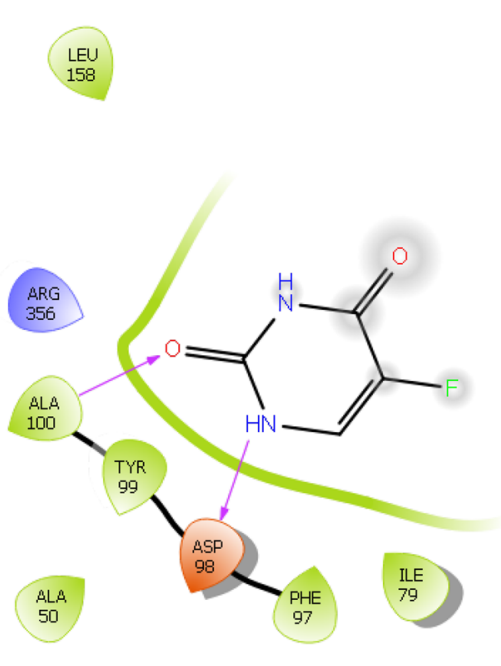

2D ligand interaction

Fig. 7 Binding surface and 2D ligand interaction diagram of 5-fluorouracil (standard drug)

Table 5 Docking results of active compounds (Ax1, Ax9 and Ax10) and standard drug

\begin{tabular}{|c|c|c|c|c|c|c|}
\hline Comp. & Docking score & $\begin{array}{l}\text { Glide } \\
\text { energy } \\
\text { (kcal/mol) }\end{array}$ & Glide emodel & XP GScore & Binding pocket residues & Interacting residues \\
\hline$A \times 1$ & -5.668 & -46.167 & -68.459 & -5.668 & $\begin{array}{l}\text { His106, Trp105, Val27, Gly28, Val35, } \\
\text { Tyr32, Arg356, Asp98, Tyr99, } \\
\text { Ala100, Ile79, Ala172, Asp173, } \\
\text { Ala50, Lys52, Phe176, Glu66, } \\
\text { Lys153, Ala155, Leu158 }\end{array}$ & $\begin{array}{l}\text { H- bond interaction with Val } 27 \text { and } \\
\text { Lys } 153 \text {, Pi cation interaction with } \\
\text { Arg356, Formation of salt bridge } \\
\text { with Asp } 173 \text { and Lys52 }\end{array}$ \\
\hline Ax9 & -4.477 & -46.551 & -64.25 & -4.477 & $\begin{array}{l}\text { Lys153, Ala155, Asn156, Leu158, } \\
\text { His106, Arg356, Glu357, Leu359, } \\
\text { Val27, Gly28, Arg29, Thr31, } \\
\text { Tyr32, Val35, Ala50, lle79, Phe97, } \\
\text { Asp173, Ala172 }\end{array}$ & H-bond interaction with Lys 153 \\
\hline$A \times 10$ & -4.191 & -42.446 & -59.884 & -4.191 & $\begin{array}{l}\text { Val27, Gly28, Thr31, Tyr32, Val35, } \\
\text { Arg356, His 106, Glu66, Phe176, } \\
\text { Asp173, Ala172, Leu158, Lys52, } \\
\text { Ala50, Phe97, Asp98, Ile79, } \\
\text { Leu70 }\end{array}$ & Pi cation interaction with Arg356 \\
\hline 5-fluorouracil & -5.753 & -21.673 & -27.685 & -5.753 & $\begin{array}{l}\text { Leu158, Val35, Arg356, Ala100, } \\
\text { Tyr99, Asp98, Phe97, Ile79, Ala50 }\end{array}$ & $\begin{array}{l}\text { H-bond interaction with Ala100 and } \\
\text { Asp98 }\end{array}$ \\
\hline
\end{tabular}

and $150 \mathrm{MHz}$, respectively by Bruker Avance III 600. ${ }^{1} \mathrm{H}-\mathrm{NMR}$ data are given as multiplicity and number of protons.

\section{Procedure for the synthesis of pyrimidine derivatives}

(Scheme 1, Ax1-Ax19)

\section{(A): Synthesis of}

1-(2-(3,4,5-trimethoxybenzylideneamino)-6-(4-nitrophenyl) pyrimidin-4-yl)-naphthalen-2-ol (Compound Ax1)

$p$-Nitroacetophenone $(0.01 \mathrm{~mol})$ and naphthaldehyde $(0.01 \mathrm{~mol})$ were added in $50 \mathrm{~mL}$ methanol after that $10 \mathrm{~mL} \mathrm{NaOH}$ solution was added drop by drop to the reaction mixture and kept on vigorous stirring for $30 \mathrm{~min}$. When the reaction mixture became turbid, it was maintained at $20-22{ }^{\circ} \mathrm{C}$ on magnetic stirrer for $4-5 \mathrm{~h}$ and then, the reaction mixture was neutralised by $0.1-$ $0.2 \mathrm{~N} \mathrm{HCl}$ to yield chalcone [Int-I]. The chalcone was filtered and recrystallised with methanol [26]. To the Int-I $(0.01 \mathrm{~mol})$, potassium hydroxide $(0.01 \mathrm{~mol})$ and guanidine nitrate $(0.25 \mathrm{M})$ in methanol $(30 \mathrm{~mL})$ was added and refluxed for $5-6 \mathrm{~h}(\mathrm{RT})$. The reaction mixture was cooled and quenched with $20 \mathrm{~mL}$ of $0.5 \mathrm{M} \mathrm{HCl}$ solution in water 


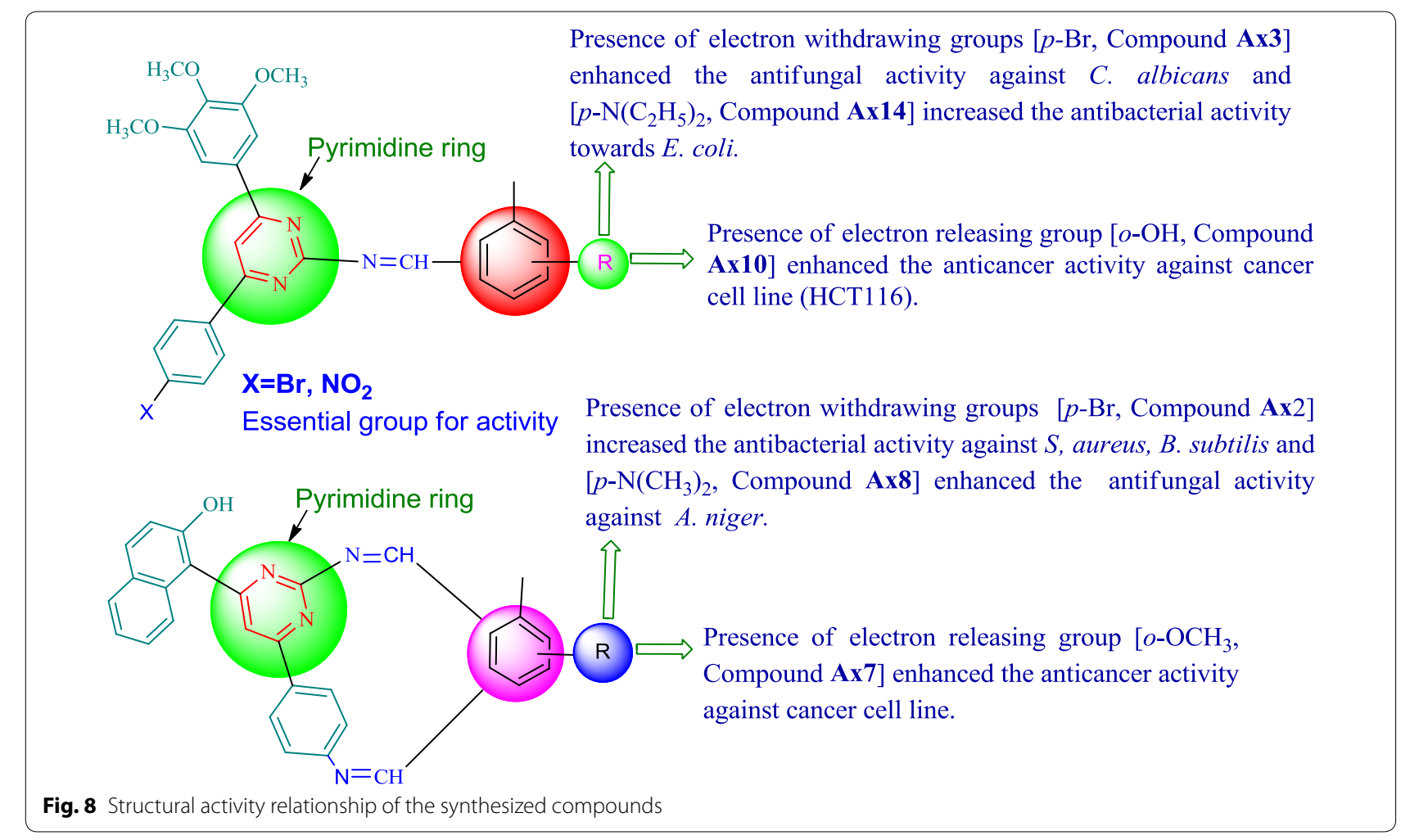

to yield pyrimidine [Int-II] [27]. The Int-II $(0.01 \mathrm{~mol})$ was then refluxed with substituted benzaldehyde $(0.01 \mathrm{~mol})$ in methanol $50 \mathrm{~mL}$ in presence of glacial acetic acid for $2-3 \mathrm{~h}(\mathrm{RT})$. The precipitate generated by adding the reaction mixture to the ice cold water was filtered and recrystallised with methanol [28].

\section{(B): Synthesis of 1-(2-substituted}

benzylideneamino)-6-(4-substituted benzylideneamino) phenyl)pyrimidin-4-yl) naphthalen-2-ol (Compounds Ax2, Ax7, Ax8 and Ax11)

$p$-Aminoacetophenone $(0.01 \mathrm{~mol})$ and naphthaldehyde $(0.01 \mathrm{~mol})$ were added in $50 \mathrm{~mL}$ methanol after that $10 \mathrm{~mL} \mathrm{NaOH}$ solution was added drop by drop to the reaction mixture and kept on vigorous stirring for $30 \mathrm{~min}$. When the reaction mixture became turbid, it was maintained at $20-22{ }^{\circ} \mathrm{C}$ on magnetic stirrer for $4-5 \mathrm{~h}$. The reaction mixture was neutralised by $0.1-0.2 \mathrm{~N} \mathrm{HCl}$ to yield chalcone [Int-I]. The chalcone was filtered and recrystallised with methanol [26]. To the Int-I $(0.01 \mathrm{~mol})$, potassium hydroxide $(0.01 \mathrm{~mol})$ and guanidine nitrate $(0.25 \mathrm{M})$ in methanol $(30 \mathrm{~mL})$ was added and refluxed for 5-6 h (RT). The reaction mixture was cooled and quenched with $20 \mathrm{~mL}$ of $0.5 \mathrm{M}$ $\mathrm{HCl}$ solution in water to yield pyrimidine [Int-II] [27]. The Int-II $(0.01 \mathrm{~mol})$ was then refluxed with substituted benzaldehyde $(0.02 \mathrm{~mol})$ in methanol $50 \mathrm{~mL}$ in presence of glacial acetic acid for $2-3 \mathrm{~h}$ (RT). The precipitate generated by adding the reaction mixture to the ice cold water was filtered and recrystallised with methanol [28].

\section{(C): Synthesis of $N$-(2-substituted}

benzylidene)-4-(4-substituted phenyl)-6-(3,4,5-trimethoxyphenyl)pyrimidin-2-amine (Compounds Ax3-Ax6, Ax9, Ax10, Ax12, Ax13, Ax14-Ax19)

$p$-Substituted acetophenone $(0.01 \mathrm{~mol})$ and 3,4,5-trimethoxybenzaldehyde $(0.01 \mathrm{~mol})$ were added in $50 \mathrm{~mL}$ methanol after that $10 \mathrm{~mL} \mathrm{NaOH}$ solution was added drop by drop to the reaction mixture and kept on vigorous stirring for $30 \mathrm{~min}$. When the reaction mixture became turbid it was maintained at $20-22{ }^{\circ} \mathrm{C}$ on magnetic stirrer for 4-5 $\mathrm{h}$ and then, the reaction mixture was neutralised by $0.1-0.2 \mathrm{~N} \mathrm{HCl}$ to yield chalcone [Int-I]. The chalcone was filtered and recrystallised with methanol [26]. To the Int-I $(0.01 \mathrm{~mol})$, potassium hydroxide $(0.01 \mathrm{~mol})$ and guanidine nitrate $(0.25 \mathrm{M})$ in methanol $(30 \mathrm{~mL})$ was added and refluxed for 5-6 h (RT). The reaction mixture was cooled and quenched with $20 \mathrm{~mL}$ of $0.5 \mathrm{M} \mathrm{HCl}$ solution in water to yield pyrimidine [Int-II] [27]. The Int-II $(0.01 \mathrm{~mol})$ was then refluxed with substituted benzaldehyde $(0.01 \mathrm{~mol})$ in methanol $50 \mathrm{~mL}$ and added few drops of glacial acetic acid for $2-3 \mathrm{~h}(\mathrm{RT})$. The precipitate generated by 
adding the reaction mixture to the ice cold water was filtered and recrystallised with methanol [28].

\section{Biological evaluations (antimicrobial and anticancer)}

The antimicrobial evaluation of developed derivatives (Ax1-Ax19) was carried out by tube dilution technique [29] towards Gram+bacteria species (S. aureus MTCC3160; B. subtilis MTCC441) and Gram- ve bacterium species (E. coli MTCC443) and fungal species: C. albicans MTCC227; A. niger MTCC281. The stock solution of compounds and control drugs (norfloxacin and fluconazole) were prepared in DMSO to get a concentration of $100 \mu \mathrm{g} / \mathrm{mL}$. Dilutions of test and reference compounds were prepared in Sabouraud dextrose broth I.P. (fungi) and double strength nutrient broth I.P. (bacteria) [30]. The test samples were incubated at $37 \pm 1{ }^{\circ} \mathrm{C}$ for $48 \mathrm{~h}$ (C. albicans), at $25 \pm 1{ }^{\circ} \mathrm{C}$ for 7 days (A. niger), $37 \pm 1{ }^{\circ} \mathrm{C}$ for $24 \mathrm{~h}$ (bacteria) respectively and the screening results were recorded in terms of MIC. The antiproliferative potency of the developed derivatives was carried out by SRB assay [23] toward human colorectal carcinoma cancer cell line [HCT116 (ATCC CCL-247)]. Data was presented as mean $\mathrm{IC}_{50}$ of triplicates.

\section{Molecular docking}

The molecular docking study was performed of the synthesized pyrimidine derivatives by GLIDE docking program of maestro $v 11.5$ (Schrodinger 2018-1). Among the docked compounds, compounds Ax1, Ax9 and Ax10 displayed moderate to good docked score within the binding pocket of the selected protein i.e. PDB Id: 5FGK with anticancer potency against a HCT116. The protein target for heterocyclic pyrimidine compounds was identified through the literature survey $[6,31]$. Pyrimidine moiety has wide spectrum of biological potential in medicinal filed [32]. CDK8 (PDB Id: 5FGK) having native ligand 5XG (co-crystallized) with good resolution about $2.36 \AA$ for docking study. Method: X-ray diffraction, $\mathrm{R}$-value free: 0.237 [33]. The root-mean-square deviation is a measure of the average distance between the atoms of superimposed structures. RMSD value of the co-crystallized native ligand (5XG) was calculated. First, Grid is generated using ATP binding site, then docking scores are calculated (Schrodinger 2018-1, maestro v11.5) [34]. Ligand preparation is done using LigPrep module of maestro v11.5. To give the best results, the molecular structures that are docked must be good representations of the actual ligand structures as they would appear in a protein-ligand complex [35].

\section{Conclusion}

In the present study, a series of heterocyclic pyrimidine compounds was synthesized in considerable yield and confirmed by FTIR, NMR, MS, CHN analysis. The synthesized compounds showed appreciable antimicrobial and antiproliferative activities. Structure activity relationship study indicated that compounds (Ax2, Ax3, Ax8 and Ax14) having electron withdrawing and compounds (Ax7 and Ax10) have electron releasing groups at substituted benzylidene aromatic nucleus exhibited significant antimicrobial and antiproliferative activities. Further, molecular docking study demonstrated that compound Ax1 showed best docked score with lowest anticancer potency and compound Ax10 showed the moderate docked score with better anticancer potency and compared to the 5-fluorouracil having better docked score with good anticancer potency. Cyclin dependent kinase-8 may be the target protein of heterocyclic pyrimidine compound for their antiproliferative potency. Based on the docking results it is suggested that more structural modifications are required in derivatives Ax1 and Ax10 to make them more potent anticancer agents and these compounds may be used as leads for the development of novel antimicrobial and anticancer agents.

\section{Abbreviations \\ NMR: nuclear magnetic resonance; IR: infrared; MS: mass spectrum; CHN: carbon hydrogen nitrogen; Str: starching; CADD: computer-aided drug design; MTCC: microbial type culture collection; E. coli: Escherichia coli; C. albicans: Candida albicans; S. aureus: Staphylococcus aureus; B. subtilis: Bacillus subtilis; A. niger: Aspergillus niger; MIC: minimum inhibitory concentration; ATCC: American Type Culture Collection; HCT116: human colorectal carcinoma 116; SRB: sulforhodamine B; SAR: structure activity relationship; $\mu \mathrm{M}$ : micro mole; CDK8: cyclin dependent kinase 8; PDB: protein data bank; RMSD: root-mean- square deviation; 2D: 2 dimensional; 3D: 3 dimensional; RNA: ribonucleic acid; DNA: deoxyribonucleic acid; $C D H$ : central drug house; RT: room temperature; DMSO: dimethyl sulfoxide; 5-Fu: 5-fluorouracil; O: ortho; p: para; EWG: electron withdrawing group.}

\section{Acknowledgements}

The authors are thankful to HOD, M.D. University, Rohtak, Haryana for providing necessary facilities to carry out this research work.

\section{Authors' contributions}

Authors BN, AK and SK- performed synthesis, antimicrobial activity and molecular docking study of active anticancer compounds; SML, KR, VM and SAAS- performed characterization and antiproliferative study of synthesized pyrimidine compounds. All authors read and approved the final manuscript.

Funding

Not applicable.

Availability of data and materials

We have presented all our main data in the form of tables and figures.

Competing interests

The authors declare that they have no competing interests.

Author details

${ }^{1}$ Faculty of Pharmaceutical Sciences, Maharshi Dayanand University, Rohtak 124001, India. ${ }^{2}$ Faculty of Pharmacy, Universiti Teknologi MARA (UiTM), 
42300 Bandar Puncak Alam, Selangor Darul Ehsan, Malaysia. ${ }^{3}$ Atta-ur-Rahman Institute for Natural Products Discovery (AuRIns), Universiti Teknologi MARA , 42300 Bandar Puncak Alam, Selangor Darul Ehsan, Malaysia. ${ }^{4}$ Collaborative Drug Discovery Research (CDDR) Group, Pharmaceutical Life Sciences Community of Research, Universiti Teknologi MARA (UiTM), 40450 Shah Alam, Selangor Darul Ehsan, Malaysia. ${ }^{5}$ Department of Pharmacology and Toxicology, College of Pharmacy, Qassim University, Buraidah 51452, Kingdom of Saudi Arabia.

Received: 7 December 2018 Accepted: 29 June 2019

Published online: 09 July 2019

\section{References}

1. Taft CA, da Silva VB, de Silva CHT (2008) Current topics in computer-aided drug design. J Pharm Sic 97(3):1089-1098. https://doi.org/10.1002/ jps.21293

2. Kakkar S, Kumar S, Narasimhan B, Lim SM, Ramasamy K, Mani V, Shah SAA (2018) Design, synthesis and biological potential of heterocyclic benzoxazole scaffolds as promising antimicrobial and anticancer agents. Chem Cent J 12(96):1-11

3. Rani J, Saini M, Kumar S, Verma PK (2017) Design, synthesis and biological potentials of novel tetrahydroimidazo[1,2-a]pyrimidine derivatives. Chem Cent J 11(16):1-11

4. Hu Y, Fu L (2012) Targeting cancer stem cells: a new therapy to cure cancer patients. Am J Cancer Res 2(3):340-356

5. Kassab A, Gedawy E (2013) Synthesis and anticancer activity of novel 2-pyridyl hexahyrocyclooctathieno [2,3-d] pyrimidine derivatives. Eur J Med Chem 63:224-230

6. Kumar S, Lim SM, Ramasamy K, Vasudevan M, Shah SAA, Selvaraj M, Narasimhan B (2017) Synthesis, molecular docking and biological evaluation of bis-pyrimidine Schiff base derivatives. Chem Cent J 11(89):1-16

7. Plewczynski D, Lazniewski M, Augustyniak R, Ginalski K (2011) Can we trust docking results? Evaluation of seven commonly used programs on PDB bind database. J Comput Chem 32(4):742-755

8. Ece A (2019) Towards more effective acetylcholinesterase inhibitors: a comprehensive modelling study based on human acetylcholinesterase protein-drug complex. J Biomol Struct Dyn. https://doi. org/10.1080/07391102.2019.1583606

9. Sherr CJ (2000) The pezcoller lecture: cancer cell cycles revisited. Cancer Res 60:3689-3695

10. Ece A, Sevin F (2013) The discovery of potential cyclin A/CDK2 inhibitors: a combination of 3D QSAR pharmacophore modeling, virtual screening, and molecular docking studies. Med Chem Res 22(12):5832-5843

11. Sayle KL, Bentley JF, Boyle TA, Calvert H, Cheng YZ, Curtin NJ, Endicott JA, Golding BT, Hardcastle IR, Jewsbury P, Mesguiche V, Newell DR, Noble MEM, Parsons RJ, Pratt DJ, Wang LZ, Griffin RJ (2003) Structure-based design of 2-arylamino-4-cyclohexylmethyl-5-nitroso-6-aminopyrimidine inhibitors of cyclin-dependent kinases 1 and 2. Bioorg Med Chem Lett 13:3079-3082

12. Ece A, Sevin F (2010) Exploring QSAR on 4-cyclohexylmethoxypyrimidines as antitumor agents for their inhibitory activity of cdk2. Lett Drug Des Discov 7(9):625-631

13. Peyressatre M, Prével C, Pellerano M, Morris MC (2015) Targeting cyclindependent kinases in human cancers: from small molecules to peptide inhibitors. Cancer 7:179-237

14. Kumar S, Narasimhan B (2018) Therapeutic potential of heterocyclic pyrimidine scaffolds. Chem Cent J 12(38):1-29

15. Kumar S, Lim SM, Ramasamy K, Vasudevan M, Shah SAA, Narasimhan B (2017) Bis-pyrimidine acetamides: design, synthesis and biological evaluation. Chem Cent J 11(80):1-14

16. Kumar S, Lim SM, Ramasamy K, Mani V, Shah SAA, Narasimhan B (2018) Design, synthesis, antimicrobial and cytotoxicity study on human colorectal carcinoma cell line of new 4,4'-(1,4-phenylene)bis(pyrimidin-2amine) derivatives. Chem Cent J 12(73):1-13

17. Guo Y, Li Jing, Ma J, Yu Z, Wang H, Zhua J, Liao X, Zhao Y (2015) Synthesis and antitumor activity of $a$-aminophosphonate derivatives containing thieno[2,3- $d$ ] pyrimidines. Chin Chem Lett 26:755-758
18. Yejella RP, Atla SR (2011) A study of anti-inflammatory and analgesic activity of new 2,4,6-trisubstituted pyrimidines. Chem Pharm Bull 59(9):1079-1082

19. Bhalgat CM, Ali MI, Ramesh B, Ramu G (2014) Novel pyrimidine and its triazole fused derivatives: synthesis and investigation of antioxidant and anti-inflammatory activity. Arab J Chem 7:986-993

20. Ashour HM, Shaaban OG, Rizk OH, El-Ashmawy IM (2013) Synthesis and biological evaluation of thieno[2', $\left.3^{\prime}: 4,5\right]$ pyrimido $[1,2-b][1,2,4]$ triazines and thieno[2,3-d] [1,2,4]triazolo[1,5-a]pyrimidines as anti-inflammatory and analgesic agents. Eur J Med Chem 62:341-351

21. Meneghesso S, Vanderlinden E, Stevaert A, McGuigan C, Balzarini J, Naesens $L$ (2012) Synthesis and biological evaluation of pyrimidine nucleoside monophosphate prodrugs targeted against influenza virus. Antivir Res 94:35-43

22. Kumar D, Khan SI, Tekwani BL, Diwan PP, Rawat S (2015) 4-Aminoquinoline-pyrimidine hybrids: synthesis, antimalarial activity, heme binding and docking studies. Eur J Med Chem 89:490-502

23. Skehan P, Storeng R, Scudiero D, Monks A, McMahon J, Vistica D, Warren JT, Bokesch H, Kenney S, Boyd MR (1990) New colorimetric cytotoxicity assay for anticancer-drug screening. J Natl Cancer Inst 82:1107-1112

24. Bassyouni F, El Hefnawi M, El Rashed A, Rehim MA (2017) Molecular modeling and biological activities of new potent antimicrobial, antiinflammatory and anti-nociceptive of 5-nitro indoline-2-one derivatives. Drug Des 6(2):1-6

25. Xu L, Zhang Y, Dai W, Wang Y, Jiang D, Wang L, Xiao J, Yang X, Li S (2014) Design, synthesis and SAR study of novel trisubstituted pyrimidine amide derivatives as CCR26 antagonists. Molecules 19:3539-3551

26. Kumar N, Jain JS, Sinha R, Garg VK, Bansal SK (2009) Evaluation of some novel chalcone derivatives for antimicrobial and anti-inflammatory activity. Der Pharmacia Lettre 1(1):169-176

27. Asiri AM, Khan SA (2011) Synthesis and antibacterial activities of a bis-chalcone derived from thiophene and its bis-cyclized products. Molecules 16:523-531

28. Sawarkar U, Narule M, Chaudhary M (2012) Synthesis of some new 3(4-hydroxyphenyl) prop-2-en-1-one 4-phenyl substituted Schiff's bases and their antibacterial activity. Der Pharma Chemica 4(2):629-632

29. Cappuccino JC, Sherman N (1999) Microbiology-a laboratory manual. Addison Wesley, California, p 263

30. Pharmacopoeia of India, vol. I (2007) Controller of Publication, Ministry of Health Department, Govt. of India, New Delhi, pp 37

31. Kumar S, Singh J, Narasimhan B, Shah SAA, Lim SM, Ramasamy K, Mani V (2018) Reverse pharmacophore mapping and molecular docking studies for discovery of GTPase HRas as promising drug target for bis-pyrimidine derivatives. Chem Cent J 12(106):1-11

32. Kaur R, Kaur P, Sharma S, Singh G, Mehndiratta S, Bedi PM, Nepali K (2015) Anti-cancer pyrimidines in diverse scaffolds: a review of patent literature. Recent Pat Anti-Cancer 10(1):23-71

33. Amin KM, Awadalla FM, Eissa AAM, Abou- Seri AM, Hassan GS (2011) Design, synthesis and vasorelaxant evaluation of novel coumarin-pyrimidine hybrids. Bioorg Med Chem 19:6087-6097

34. Singh J, Kumar M, Mansuri R, Sahoo GC, Deep A (2016) Inhibitor designing, virtual screening and docking studies for methyltrans-ferase: a potential target against dengue virus. J Pharm Bioallied Sci 8(3):188-194

35. Driessche GVD, Fourches D (2017) Adverse drug reactions triggered by the common HLA-B*57:01 variant: a molecular docking study. J Cheminform 9(13):1-17

\section{Publisher's Note}

Springer Nature remains neutral with regard to jurisdictional claims in published maps and institutional affiliations. 